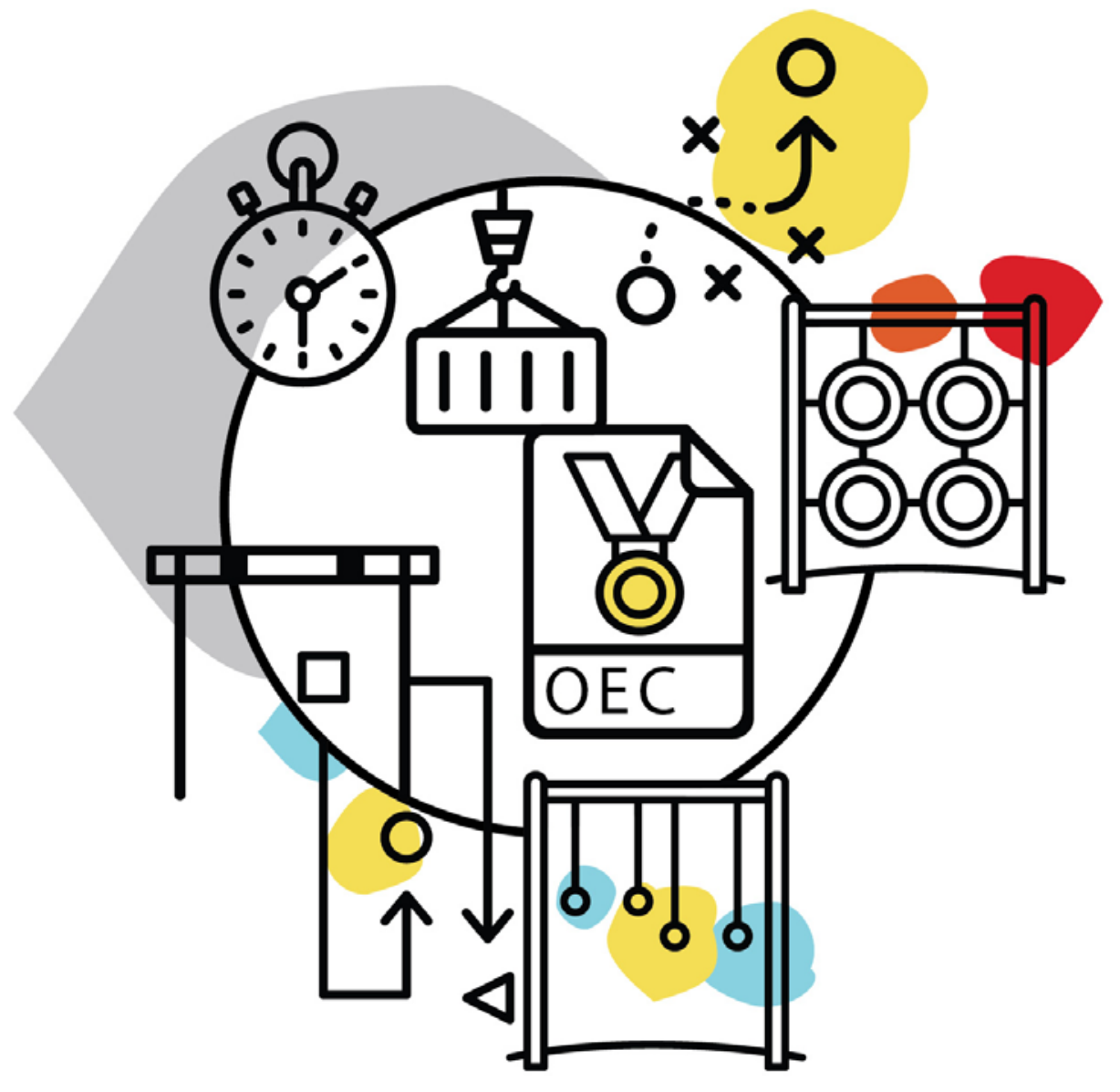

\title{
APLICACIÓN DEL ESTÁNDAR OEC EN UN OPERADOR LOGISTICO
}

(1) DEPARTAMENTO DE INNOVACIÓN Y DESARROLLO EN GESTIÓN, GERENCIA DE TECNOLOGÍA Y GESTIÓN, LATU.

(2) COORDINACIÓN DEL SISTEMA DE GESTIÓN INTEGRADO, RALESUR S.A. os servicios logísticos y de comercio internacional han tenido un crecimiento sostenido en nuestro país durante la última década. Esto ha implicado que las empresas afectadas se adecuaran a los requerimientos normativos a nivel internacional sobre seguridad en el comercio para asegurar la continuidad de sus operaciones (Organización Mundial de Aduanas, 2015). 
A nivel regional, el Banco Interamericano de DesarroIlo (BID) ha promovido y financiado la implementación del programa Operador Económico Autorizado (OEA), que surgió como una homologación de requerimientos de seguridad de la Organización Mundial de Aduanas (OMA), y que es certificable por parte de las aduanas integrantes de esta organización.

En Uruguay esta iniciativa es denominada Operador Económico Calificado (OEC) y es liderada por el departamento homónimo de la Dirección Nacional de Aduanas (DNA). Sus objetivos son contribuir al incremento de la competitividad del sector privado de la región y el mundo, alentar la inserción internacional de la economía nacional, promover la eficiencia de la actuación aduanera y fortalecer la seguridad en la cadena de suministro (Uruguay, 2015).

Este artículo relata la experiencia de implementación de los requerimientos del estándar OEC de la DNA en un operador logístico nacional y su integración al sistema de gestión existente en la empresa.

\section{El estándar OEC - DNA / OMA}

La iniciativa Operador Económico Autorizado (OEA) comenzó en Uruguay a partir de la firma del acuerdo de entendimiento entre la Dirección Nacional de Aduanas (DNA) y el Banco Interamericano de Desarrollo (BID), y la Orden del día 37/2007 de 2007 (Uruguay, Dirección Nacional de Aduanas, 2007). En 2009 se emitieron dos órdenes del día adicionales, 113 y 121/2009 (Uruguay, Dirección Nacional de Aduanas, 2009a y 2009b), para promover la instalación del programa OEA en el país.

El BID ha impulsado la implementación de estos programas en América Latina. Los proyectos iniciales en Colombia, Panamá, Perú, República Dominicana y Uruguay se financiaron con el Fondo General de Cooperación de España. Otro de los cometidos de esta iniciativa es facilitar acuerdos de reconocimiento mutuo entre las aduanas de los países partícipes y de bloques extrarregionales.

En 2011 se conformó el grupo de trabajo responsable del diseño e implementación del programa y de la posterior ejecución de un plan piloto entre junio y agosto de 2013.

El documento de referencia para la implementación fue Guías prácticas para el diseño e implementación de un programa de Operador Económico Autorizado en América Latina (Organización Mundial de Aduanas y
Banco Interamericano de Desarrollo, 2011), que recoge la experiencia de implementación de programas similares en otros países.

A nivel de la DNA se creó el Departamento Operador Económico Calificado con los objetivos de implementar, difundir y desarrollar el programa OEC. La iniciativa es, a su vez, uno de los pilares del proyecto de modernización de la DNA derivados de su misión y visión.

Entre los objetivos del programa OEC se destacan:

- Contribuir al incremento de la competitividad del sector privado de la región y el mundo a través de la reducción de tiempos y costes, y la generación de oportunidades de mejora de los procesos y prácticas de los operadores.

- Alentar la inserción internacional de la economía nacional mediante acuerdos de mutuo reconocimiento entre las aduanas, para mejorar el acceso a los mercados del sector privado.

- Promover la eficiencia de la actuación aduanera a través de la incorporación de buenas prácticas y estándares internacionales, y la creación de capacidad para la gestión.

- Fortalecer la seguridad en la cadena de suministro con controles certificados en cada uno de sus eslabones, asegurando que la mercadería llegue a destino sin alteraciones.

A la fecha, 41 empresas uruguayas están certificadas según el estándar OEC, con predominio del sector de servicios logísticos y despachantes de aduanas.

\section{Sobre la metodología de implementación}

Según la DNA, "el OEC busca crear una alianza de participación voluntaria aduana - empresa para construir relaciones de cooperación que mejoren y aseguren la cadena de suministro internacional. Las empresas que forman parte de la cadena deben asegurar la integridad de sus medidas de seguridad y deben estar documentadas" (Dirección Nacional de Aduanas, [s.d.]b).

Para lograr este objetivo, la metodología de implementación del estándar OEC establece que se deberá realizar un análisis de los riesgos asociados a la cadena de 
suministro internacional de la que la empresa es partícipe e implementar acciones orientadas a:

- Minimizar el grado de vulnerabilidad de la empresa a ser involucrada en actos ilícitos como el contrabando, la falsificación, el narcotráfico o el terrorismo.

- Asegurar la trazabilidad de las operaciones asociadas al comercio internacional con el fin de identificar fallas y deslindar responsabilidades.

- Evitar la ocurrencia de eventos que afecten la continuidad de la cadena logística y contar con planes de contingencia.

El estándar también establece como requisitos que la empresa cuente con una política de seguridad documentada y difundida a los socios comerciales, y con procedimientos documentados para la evaluación del riesgo de toda su cadena de suministro.

OEC establece que las organizaciones deben gestionar los siguientes criterios de seguridad:

1. Seguridad en relación a los socios comerciales.

2. Seguridad en las unidades de transporte de carga.

3. Seguridad de las mercaderías.

4. Seguridad en el acceso de personas.

5. Seguridad física en las instalaciones.

6. Seguridad en la contratación del personal.

7. Seguridad de la información.

\section{Aplicación en un operador logístico}

Como parte de su estrategia de mejora continua, la empresa Ralesur S.A. decidió en el año 2015 integrar a su sistema de gestión el estándar OEC de la DNA.

Ralesur es una empresa nacional proveedora de servicios logísticos con una posición de liderazgo en volumen de tráfico e innovación tecnológica. Está asociada a la red DB Schenker, perteneciente al grupo Deutsche Bahn de ferrocarriles alemanes, primer operador de transporte ferroviario y carretero en Europa, segundo operador aéreo y tercer operador marítimo en el mundo, con más de 96.000 empleados distribuidos en 2000 oficinas en 130 países.

Acorde a su filosofía corporativa, la empresa practica el concepto de proveedor integral de servicios logísticos, dando solución a todos los requerimientos de un transporte internacional puerta a puerta, incluyendo servicios de almacenaje o despachos aduaneros como opciones adicionales. Su negocio se basa en el compromiso con los siguientes principios:

- Aprovechamiento de las ventajas de la red mundial DB Schenker.

- Generación de valor agregado para los clientes a través de soluciones logísticas creativas y eficientes.

- Utilización de tecnologías de avanzada.

- Mejora continua aplicada a los procedimientos.

- Inversión y capacitación de los recursos humanos.

- Rentabilidad y crecimiento sustentables.

A efectos de dar cumplimiento a los requisitos establecidos en el estándar de referencia, la empresa contrató los servicios de consultoría del Laboratorio Tecnológico del Uruguay (LATU) para la implementación de OEC, y contó con el apoyo de la Agencia Nacional de Investigación e Innovación (ANII) a través del instrumento denominado Certificación y nuevos mercados de exportación 2015.

Se estableció como objetivo general del proyecto el logro de la certificación de su Sistema de Gestión de la Seguridad en el Comercio Internacional en un plazo de 10 meses. La certificación del sistema era una de las condicionantes para acceder al subsidio de la ANII.

Para llevar adelante la consultoría se conformó un equipo de trabajo multidisciplinario designado por la empresa que actuó como contraparte del equipo consultor del LATU, alternando la participación de sus integrantes según las temáticas que se iban abordando.

Ralesur ya contaba con un Sistema de Gestión de la Calidad (SGC) certificado según la norma UNIT ISO 9001:2008 (Instituto Uruguayo de Normas Técnicas, 2008). También contaba con experiencia en la gestión de la seguridad en el comercio internacional, ya que la empresa había certificado sus procesos de control de la cadena de suministro según el estándar BASC versión 2005 (World BASC Organization, 2005). Por este motivo uno de los desafíos del proyecto era la integración armónica de los nuevos requisitos con los ya asumidos por la empresa.

El proyecto comenzó con un diagnóstico para evaluar el grado de conformidad general con los requisitos correspondientes a un Sistema de Gestión de Seguridad en el Comercio Internacional, según lo establecido en el estándar OEC. La referencia para esta actividad fue la lista de verificación para la autoevaluación de empresas, publicada por el Departamento de OEC de la DNA (Dirección Nacional de Aduanas, [s.d.]a). El diagnóstico realizado durante noviembre de 2015 per- 
mitió contrastar la situación de la empresa en relación al estándar. Dado que la organización ya contaba con un Sistema de Gestión de la Calidad implementado y certificado, el diagnóstico se focalizó en los aspectos ligados a la gestión de la seguridad y se verificó la vigencia de las prácticas ya implementadas y de la documentación desarrollada anteriormente. Con base en las conclusiones del diagnóstico se actualizó el plan de acción general de trabajo previsto para el proyecto.

La implementación del Sistema de Gestión de Seguridad en el comercio internacional alcanzó todos los procesos de la empresa y fue liderada por parte de la Coordinación de Calidad de Ralesur. Para este cometido se trabajó en diferentes instancias con las contrapartes responsables de gerenciar y ejecutar los procesos de la empresa de acuerdo al cronograma acordado para el proyecto.

En términos generales, las prácticas ligadas al control de la infraestructura no se encontraban sistematizadas y las relacionadas con seguridad de la información no estaban actualizadas en función de los niveles de seguridad requeridos para uno de los principales activos de la empresa. No obstante, se detectaron fortalezas en los procesos de gestión de los recursos humanos, la planificación estratégica, la gestión de socios comerciales y la evaluación de riesgos.

El plan de acciones que se elaboró a partir del diagnóstico fue validado con la empresa. Establecía tres niveles de prioridad para las acciones que se identificaron, con énfasis en las áreas de gestión que presentaban las mayores brechas respecto a los requisitos del estándar OEC. Además, detallaba las actividades necesarias para dar cumplimiento a los requerimientos para un operador logístico, los responsables de ejecutar esas acciones, las herramientas a implementarse y los plazos de ejecución.

Las primeras acciones estaban destinadas a establecer la estrategia de seguridad que debería incorporar la empresa. Para cumplir con este objetivo se priorizó la definición de las responsabilidades de seguridad, la designación de un representante de la dirección y de los responsables de los diferentes procesos y, según el caso, se actualizaron los perfiles de los puestos. Asimismo, se redactó, aprobó y difundió la Política de Seguridad de Ralesur S.A.

Tomando como referencia este documento se definieron los objetivos de seguridad y se estableció para ellos la modalidad de aprobación, seguimiento y revisión. La estructura de medición se complementó con la sistematización de la metodología para el análisis y medición de los procesos.
Durante la implementación de los requisitos del estándar OEC, la empresa estaba migrando a la modalidad de Cuadro de Mando Integral para la medición del desempeño de su negocio. Por esta razón los objetivos de seguridad se integraron a las cuatro dimensiones consideradas en esta metodología de gestión.

En sintonía con la visión, la estrategia de seguridad y los objetivos definidos por Ralesur, el plan de acción se centró en las etapas relevantes del proceso de gestión del comercio exterior. En su diseño se contemplaron las interrelaciones entre las operaciones, la gestión de la seguridad de la información, de los recursos humanos y de los socios comerciales (clientes y proveedores) a lo largo de la cadena.

Dado que buena parte del personal de la empresa no había participado del proceso de implementación del sistema de gestión integrado con alcance a calidad y seguridad, se realizaron una serie de talleres en los que se profundizó sobre las áreas de gestión que se iban a desarrollar en el transcurso de la implementación y que iban a requerir el apoyo de las diferentes áreas de la empresa. A esto se sumó el cometido de socializar e informar a la interna sobre el alcance y objetivos del proyecto, en el entendido de la relevancia del compromiso de todos los integrantes con los requerimientos del estándar. Los talleres abordaron los siguientes temas:

- Alcance del proyecto, requisitos del estándar OEC y Sistemas de Gestión Integrados.

- Gestión de documentos y seguridad de la información.

- Seguridad en el transporte.

- Gestión de seguridad física y recursos humanos.

- Gestión de riesgos.

Para realizar una puesta a punto de la evaluación de riesgos de la empresa con foco en la gestión de la seguridad se utilizó el análisis modal de fallos y efectos. Esta herramienta ya era utilizada por la empresa para evaluar los riesgos asociados a la gestión de la calidad de sus procesos y es la recomendada por la DNA para dar cumplimiento a ese requisito excluyente. Para la realización de este análisis con foco en la gestión de la seguridad, participaron integrantes de los diferentes procesos de Ralesur S.A., tanto a nivel de mandos medios como operativos. Como resultado de este ejercicio se identificaron, evaluaron y valorizaron los riesgos asociados a las actividades de comercio internacional. El análisis se complementó con el establecimiento de las acciones necesarias para reducir el nivel de riesgo a valores aceptables para la empresa. 
Se realizó una revisión y adecuación de toda la documentación necesaria para que el sistema de gestión integrado diera cumplimiento al estándar de referencia en base a una metodología de trabajo participativa entre los principales involucrados. Estos documentos fueron el manual de gestión, los planes de calidad, los procedimientos y los instructivos. Se elaboraron los procedimientos que no estaban contemplados por parte de la empresa y se diseñaron, revisaron, actualizaron e implementaron los registros requeridos para cumplir con los requisitos de OEC - DNA.

En cuanto a la infraestructura para la seguridad física, se realizó una optimización de la cantidad y distribución de las cámaras de videovigilancia y de los dispositivos de control de acceso para las áreas que se identificaron como restringidas. A esto se sumó la revisión del procedimiento de control de acceso para el personal, proveedores y visitantes de la empresa.

Se conformó un equipo de auditoría interna para evaluar el grado de avance de la implementación previo a las instancias de certificación. Este equipo estuvo integrado en su totalidad por personal de la empresa, ya que varios integrantes contaban con formación y experiencia en la realización de auditorías internas de calidad y seguridad.

La actividad final de la consultoría de implementación fue la revisión general del sistema implementado por parte de la dirección. En el informe que surgió de esta revisión se detallaron las actividades realizadas en el marco del proyecto, el estado del sistema de gestión y las recomendaciones de mejora.

Concluida la auditoría externa de setiembre de 2016, la empresa logró la recomendación de certificación del equipo auditor de la DNA.

\section{Potenciales y desafíos}

El enfoque complementario de OEC hace que la implementación del estándar sea de fácil integración en organizaciones que ya cuentan con otros sistemas de gestión. Su diseño compatible favorece las sinergias entre uno y otros.

En el caso de Ralesur los requerimientos del estándar de referencia se han mantenido vigentes a través de:

- El mantenimiento de las buenas prácticas de seguridad, que hoy están documentadas y son trazables.

- La realización de talleres de análisis de riesgo, a través de la herramienta análisis modal de fallos y efectos, con los socios comerciales para apoyarlos en la implementación de las herramientas del estándar y reforzar el enfoque de cadena.

- La transferencia de la experiencia del conocimiento adquirido en la implementación a socios comerciales que han consultado sobre lo que implica incorporar el estándar OEC en una empresa.

Mediante la práctica de encuestas de satisfacción personalizadas, Ralesur ha corroborado que sus clientes valoran la gestión de seguridad y que eso los ha convertido en referentes para ellos y ha posicionado su servicio.

Por su parte, la DNA ha verificado la vigencia del sistema de gestión a través de la primera auditoría externa de seguimiento que tuvo lugar en setiembre de 2017, y mantiene vigente la certificación para la empresa. El desafío para Ralesur es continuar con los ciclos de mejora continua de su gestión de la seguridad, de acuerdo a los requerimientos de OEC, y con la evaluación permanente del entorno.

Es importante señalar que, a la fecha, aún existen pocos convenios de cooperación con aduanas de otros países. En la medida en que estos objetivos de la Dirección Nacional de Aduanas se concreten, serán un factor motivador para que otras empresas, en particular los exportadores, visualicen la incorporación del estándar OEC como una herramienta que incremente su competitividad en el comercio internacional y se puedan consolidar cadenas completas con todos sus integrantes certificados.

\section{Referencias}

Instituto Uruguayo de Normas Técnicas, 2008. UNIT-ISO 9001: Sistemas de gestión de la calidad - requisitos. Montevideo: UNIT.

Organización Mundial de Aduanas y Banco Interamericano de Desarrollo, 2011. Guías prácticas para el diseño e implementación de un Programa de Operador Económico Autorizado (OEA) en América Latina [En línea]. s.I.: OMC y BID. [Consulta: 12 de setiembre de 2017]. Disponible en: http://www.aduanas.gub.uy/innovaportal/ file/11811/1/guias_practicas_para_el_diseno_e_implementacion_de_un_programa_de_oea_en....pdf

Organización Mundial de Aduanas, 2015. Marco normativo SAFE para asegurar y facilitar el comercio, 2015 [En línea]. Montevideo: Dirección Nacional de Aduanas. 
[Consulta: 12 de setiembre de 2017]. Disponible en: http://www.aduanas.gub.uy/innovaportal/file/11811/1/ marco_safe_2015_en_espanol.pdf

Uruguay. Decreto 210/015, de 03 de agosto de 2015. Diario Oficial, 11 de agosto de 2015. No. 29.269, p. 16.

Uruguay. Dirección Nacional de Aduanas, 2007. Orden del día 37/2007 Grupo de Trabajo Relativo al Operador Económico Autorizado [En línea]. Montevideo: Dirección Nacional de Aduanas. [Consulta: 12 de setiembre de 2017]. Disponible en: http://www.aduanas.gub.uy/innovaportal/v/2103/9/innova.front/orden-del-dia-37_2007.html

Uruguay. Dirección Nacional de Aduanas, 2009a. Orden del día 113/2009 Designación Coordinadora Programa de Operador Económico Autorizado [En línea]. Montevideo: Dirección Nacional de Aduanas. [Consulta: 12 de setiembre de 2017]. Disponible en: http://www.aduanas.gub.uy/innovaportal/v/2334/9/innova.front/orden-del-dia-113_2009.html

Uruguay. Dirección Nacional de Aduanas, 2009b. Orden del día 121/2009 Designación del Grupo de Trabajo para el Programa de Operador Económico Autorizado [En línea]. Montevideo: Dirección Nacional de Aduanas. [Consulta: 12 de setiembre de 2017]. Disponible en: http:// www.aduanas.gub.uy/innovaportal/v/2342/9/innova. front/orden-del-dia-121_2009.html

Uruguay. Dirección Nacional de Aduanas, [s.d.]a. Formulario de autoevaluación OEC [En línea]. Montevideo: Dirección Nacional de Aduanas. [Consulta: 12 de setiembre de 2017]. Disponible en: http://www.aduanas.gub.uy/innovaportal/file/11998/1/oec.rg.03.v02_formulario_de_autoevaluacion_oec._pdf_rellenable.pdf

Uruguay. Dirección Nacional de Aduanas, [s.d.]b. Manual de seguridad para la cadena de suministro. [En línea]. Montevideo: Dirección Nacional de Aduanas. [Consulta: 12 de setiembre de 2017]. Disponible en: http://www. aduanas.gub.uy/innovaportal/file/11811/1/manual_de_seguridad_oec.pdf

World BASC Organization, 2005. Estándar BASC versión 2: Gestión de control y seguridad. Miami: World BASC Organization

\section{Enlaces recomendados}

Dirección Nacional de Aduanas - www.aduanas.gub.uy Organización Mundial de Aduanas - www.wcoomd.org Organización Mundial de Comercio - www.wto.org Mercosur - www.mercosur.int Banco Interamericano de Desarrollo - www.iadb.org/es Programa CTPAT - www.cbp.gov/xp/cgov/trade/cargo-security/ctpat

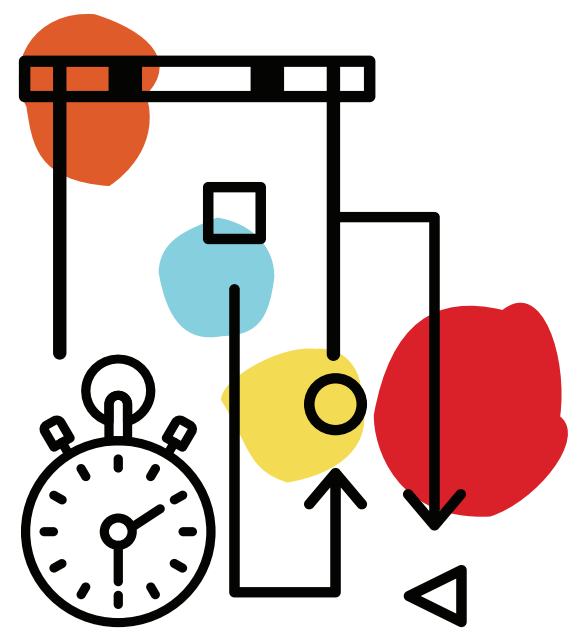

